\title{
Autonomeação \\ e autoclassificação \\ das homossexualidades \\ masculinas e sexualidades \\ alternativas no Brasil
}

\author{
Francisco Arrais Nascimento* \\ Luis Fernando Herbert Massoni** \\ Rafael da Silva Shirakava* \\ Fabio Assis Pinho*** \\ Daniel Martínez-Ávila***
}

\section{Artículo recibido: \\ 23 de octubre de 2019 \\ Artículo aceptado: \\ 7 de marzo de 2020}

Artículo de investigación

\section{Resumo}

Objetivou-se compreender as autonomeações praticadas em aplicativos de interação social de forma a esboçar uma classificação do domínio das homosexualidades masculinas, modalidades alternativas de sexualidade e de desejo no Brasil. O estudo qualitativo de cunho documental, apoiado em pesquisa bibliográfica, sob a forma de cartografia, tem como corpus 1.732 palavras extraídas de 1.005 títulos de perfis de usuários do Scruff (aplicativo mobile de interação social utilizado por homens que buscam relacionar-se

\footnotetext{
* $\quad$ Universidade Estadual Paulista "Júlio de Mesquita Filho" (UNESP), Brasil francisco.arrais.nascimento@gmail.com rafael.2015.shirakava@gmail.com ** Universidade Federal do Rio Grande do Sul (UFRGS), Brasil luisfernandomassoni@gmail.com $\star \star \star$ Universidade Federal de Pernambuco (UFPE), Brasil fabiopinho@ufpe.br $\star \star \star \star$ Universidad Carlos III (UC3M), España_dmartine@bib.uc3m.es INVESTIGACIÓN BIBLIOTECOLÓGICA, vol.34, núm. 84, julio/septiembre, 2020, México, ISSN: 2448-8321 pp. 151-168
} 
afetivo-sexualmente com outros homens), recorrendo-se à técnica de Mineração de Textos por meio do software Voyant Tools, permitindo a visualização de correlações, coocorrências, fluxos e dispersão de temáticas textuais, além da técnica de análise de conteúdo para identificação dos principais assuntos contemplados no corpus. Assim, em sua autoclassificação, alguns sujeitos utilizam termos que provocam deslizamentos de sentido, afastando-os da identidade homossexual e reforçando sua masculinidade, baseando-se em estereótipos e preconceitos.

Palavras-chave: Domínio das Homossexulidades; Classificação; Modalidades Alternativas de Sexualidade; Autonomeação; Autoclassificação

\section{Autodenominación y autoclasificación de la homo- sexualidad masculina y las sexualidades alternativas en Brasil \\ Francisco Arrais Nascimento, Luis Fernando Herbert Massoni, Rafael da Silva Shirakava, Fabio Assis Pinho y Daniel Martínez-Ávila \\ RESUMEN}

El objetivo de este estudio fue comprender las prácticas de autodenominación en aplicaciones sociales de interacción para desarrollar una clasificación de la homosexualidad masculina, sexualidades alternativas y deseo en Brasil. El presente estudio cualitativo, basado en una investigación documental y bibliográfica en forma de cartografía, trabajó con un corpus de 1732 palabras extraídas de 1005 perfiles de usuario en Scruff (una aplicación móvil de interacción social utilizada por hombres que buscan relacionarse afectiva y sexualmente con otros hombres). Se utilizó el software de minería de datos Voyant Tools, el cual permitió la visualización de correlaciones, coincidencias, flujos y dispersión de temas textuales, así como análisis de contenido para identificar los principales temas del corpus. Se concluye que, en su autoclasificación, algunos sujetos usan términos que provocan ligeros cambios de significado, a la vez que se distancian de una identidad gay y refuerzan su masculinidad basándose en estereotipos y prejuicios. 
Palabras clave: Dominio de Homosexualidades; Clasificación; Modalidades Alternativas de Sexualidad; Audenominación; Autoclasificación

Self-naming and self-classification of gay men and alternative sexualities in Brazil

Francisco Arrais Nascimento, Luis Fernando Herbert Massoni, Rafael da Silva Shirakava, Fabio Assis Pinho and Daniel Martínez-Ávila

\section{Abstract}

The aim of this study was to understand the practices of self-naming in social applications of interaction in order to outline a classification of male homosexuality, alternative sexualities, and desire in Brazil. This qualitative study, based on a documentary and bibliographic research in the form of cartography, worked with a corpus of 1,732 words extracted from 1,005 user profiles on Scruff (a cellphone social interaction application used by men who seek to relate affectivelysexually with other men). We used the data mining Voyant Tools software that allowed the visualization of correlations, co-occurrences, flows, and dispersion of textual themes, as well as the technique of content analysis in order to identify the main subjects in the corpus. We found out that, in their self-classification, some subjects use terms that provoke slight changes of meaning, distancing themselves from a gay identity, and reinforcing their masculinity while relying on stereotypes and prejudices.

Keywords: Domain of Homosexuality; Classification; Alternative Modalities of Sexuality; Selfnaming; Self-classification

\section{INTRODUÇÃO}

luta pelos direitos da comunidade LGBTQIA $+{ }^{1}$ esbarra em barreiras de
acordo com cada contexto sociocultural específico. Assim, a identidade

1 Sigla que designa a multiplicidade de orientações sexuais e variações de gênero, como: Lésbicas, Gays, Bissexuais, Transexuais, Queer, Intersexuais, dentre outros. 
coletiva de cada grupo social também influencia nessa aceitação da homossexualidade e das modalidades alternativas de sexualidade, pois sua construção é sempre calcada na escolha de características que se deseja elucidar como adequadas ou comuns ao grupo social, formando uma narrativa sobre o que é ser membro do grupo e o que se espera desse membro. Ou seja, uma identidade coletiva está sempre permeada por um discurso homogeneizador. Percebe-se que é travada uma luta dos homossexuais por visibilidade e significação como membros diferentes (e tradicionalmente discriminados) versus uma luta dos homossexuais pela normalidade, enquanto pessoas sem diferenças com o resto da população.

A sexualidade é uma dessas características engendradas pela identidade coletiva, pois a heterossexualidade é comumente compreendida como padrão a ser seguido e referência de normalidade, algo que se manifesta inclusive na linguagem utilizada pelo grupo: mais do que meramente explorar e descrever sistemas de classificação do conhecimento, os estudos terminológicos apresentam-se como uma possibilidade de reflexão acerca das práticas de classificação social, revelando formas de representação dos sujeitos através da linguagem compartilhada pelo grupo. Estudar essa linguagem partilhada é refletir sobre processos de identificação e autoidentificação, em um universo que engloba tanto o sujeito e seus desejos (a identidade individual) como o sujeito e os papéis sociais que este deseja assumir (a identidade individual em consonância com a identidade coletiva).

Pensando nisso, propõe-se um estudo acerca da terminologia utilizada por homens que utilizam o Scruff, aplicativo de relacionamento afetivo-sexual, para compreender como esses sujeitos identificam a si mesmos através dos termos que utilizam para se representar no aplicativo. A partir dessa análise, é possível perceber os deslizamentos de sentido promovidos através de termos desviantes que mascaram ou atenuam a condição homossexual, tornando-a mais aceitável perante os padrões socialmente impostos e à identidade que se pretende assumir.

\section{TERMINOLOGIA, IDENTIDADE E O PODER DE NOMEAR NO DOMÍNIO DAS HOMOSSEXUALIDADES}

Os sistemas de organização do conhecimento utilizados tradicionalmente em bibliotecas e ambientes de informação incluem listas de cabeçalhos de assunto, classificações, listas de autoridades, diretórios, taxonomias, tesauros, redes semânticas e ontologias (Mazzocchi, 2018). Outras classificações de sistemas de organização do conhecimento na Ciência da Informação têm 
incluído também as folksonomias (Souza, Tudhope e Almeida, 2012), às quais são desenvolvidas considerando os termos propostos pelos usuários através de ferramentas colaborativas, redes sociais, etc.

O "poder de nomear" é um ato político (Olson, 2002) para além da função do indexador, originalmente concebido como um poder e responsabilidade que o bibliotecário tem ao criar substitutos para documentos em sistemas de organização do conhecimento. Outra dimensão desse conceito é o "poder de auto-nomeação" (Campbell et al., 2017), exercido quando comunidades específicas e marginalizadas decidem representar assuntos específicos usando novos termos que podem servir como um código de comunicação entre os membros da comunidade, incluindo também outros propósitos, como identificação e proteção.

Tal poder é exercido tradicionalmente pela norma estabelecida, seja ela econômica, de raça, de gênero, sexualidade ou qualquer outra relação de poder no âmbito da sociedade, podendo ser traduzida nos sistemas de organização do conhecimento (Martínez-Ávila, Semidão e Ferreira, 2016) e refletidas inevitavelmente na ordem estabelecida nos sistemas (Martínez Ávila e Guimarães, 2013; Martínez-Ávila, Ferreira e Magro, 2015). Logo, compreende-se que "O poder produz saber [...], não há relação de poder sem constituição correlata de um campo de saber, nem saber que não suponha e não constitua ao mesmo tempo relações de poder" (Foucault, 2013: 30). Um exemplo disso é o ambiente LGBTQIA+, cujas características distintas levam não só a uma riqueza de vocabulários de especialidade, mas também a uma tensão entre a proximidade e o significado, como estudado por Campbell (2000).

Moreira (2011: 2919) ressalta que, no ato de nomear, "as posições sociais de quem nomeia e do que é nomeado devem ser obedecidas, e essas posições revelam quem tem poder e autoridade para nomear e quem, ou o que, está subordinado a esse poder". Desse modo, não seria o mesmo um ato de nomeação e criação de sistemas de organização do conhecimento voltados a uma comunidade específica por sujeitos de dentro da comunidade ou por sujeitos externos a ela, tanto no processo de uma construção de uma identidade como de sua desclassificação (García Gutiérrez, 2009).

Esta visão na construção de sistemas de organização do conhecimento corresponde à abordagem historicista-pragmatista ou de análise de domínio de Hjørland (Mazzocchi, 2018), oposta principalmente a abordagens racionalistas e empiristas e a qual também inclui explicitamente epistemologias feministas (Hjørland, 2013). Nesta visão epistemológica ou de análise de domínio, o ponto de partida seria que diferentes comunidades poderiam estar interessadas em um mesmo objeto, mas fazendo uma interpretação diferente, outorgando um valor informacional, dependente do ponto de vista da comunidade específica (Hjørland, 2002, 2016; Mai, 2011). 
Mesmo Birger Hjørland discutiu sua classificação de famílias epistemológicas, onde se insere nossa abordagem na teoria do conceito (Hjørland, 2009; Machado, Martínez-Ávila e Simões, 2019). No seu mais recente trabalho sobre analise de domínio, publicado no periódico Knowledge Organization (Hjørland, 2017: 455), afirma que "Keilty and Smiraglia (2016) is a study of male homossexual communication on an Internet contact site, which provides an argument for considering this a domain. It is clearly an example of a domain that is an alternative to an academic discipline". No trabalho de Keilty e Smiraglia (2016), se trabalha com o termo utilizado em aplicativos de relacionamentos como elemento representador e comunicador no domínio.

Diante disso, se pode vislumbrar sob o recorte das masculinas e modalidades alternativas de sexualidade no Brasil, em um intercurso margem-centro, por se tratar de construir e representar uma categoria social dominada, constituída sobre termos negativos em função da transgressão à norma, devendo-se levar em consideração que sua representação envolve o rompimento com as categorias de percepção que fundamentam a inferioridade (Bourdieu, 2002). Esse rompimento permitiria que experiências vividas de forma tácita ou dissimulada ganhassem visibilidade a partir de sua enunciação pública e que se construam signos de pertencimento a um grupo social, a uma identidade sob o viés desconstrutor do dispositivo de controle proposto por Deleuze (1996), que compreende a cartografia como um método para além de seus usos limitados dentro da Geografia, onde o autor aloca a mesma como uma alternativa para "desemaranhar" as linhas que compõem um dispositivo.

Os dispositivos suscitam a percepção de discursos hegemônicos que regulam e instauram normas, produzem "verdades" e assim prevalecem e são perpetuados (Foucault, 2000). Um exemplo do que fora supracitado é a proibição, no Brasil, de doação de sangue por Homossexuais e Homens que Fazem Sexo com Homens (HSH). Nesse contexto, duas normas administrativas proíbem que o sangue seja sequer coletado no país, a saber: o artigo 64 da portaria 158/2016 do Ministério da Saúde que considera "inapto temporário por 12 meses homens que tiveram relações sexuais com outros homens e/ou as parceiras sexuais destes" e o artigo 25 da Resolução da Diretoria Colegiada (RDC) 34/2014 da Agência Nacional de Vigilância Sanitária (Anvisa) que estabelece "os contatos sexuais que envolvam riscos de contrair infecções transmissíveis pelo sangue devem ser avaliados e os candidatos nestas condições devem ser considerados inaptos temporariamente por um período de 12 meses, incluindo-se indivíduos do sexo masculino que tiveram relações com outros indivíduos do mesmo sexo e/ou as parceiras destes". Cabe ressaltar que os dispositivos do Ministério da Saúde e da Anvisa ferem o direito à igualdade e o direito à dignidade da pessoa humana previstos na Constituição Federal 
(CF), ao estabelecerem critério discriminatório, utilizando-se da orientação sexual do sujeito para promover o impedimento do mesmo.

Adentrar ao domínio das sexualidades enquanto dispositivo (Foucault, 1988) permite compreendê-las como campo onde o poder disciplinar e a biopolítica entrelaçam-se em uma estratégia de controle simultaneamente individualizante e massificador (Foucault, 1988; 2000). Logo, concebe-se que toda construção, seja de um sujeito ou de uma identidade, envolve certo grau de normatização, cujo efeito é a produção de excluídos (Miskolci, 2009), revelando-se a intenção de criar corpos sexuados e neles inserir a "natural binaridade" (masculino e feminino), onde ancora-se a gênese de uma realidade baseada na negação, consolidando estereótipos que certificam o padrão heteronormativo de masculinidade e/ou feminilidade (Badinter, 1993).

A sexualidade é o comportamento humano menos natural, pois sendo os caminhos da sexualidade constituintes de formas de expressão, de prazer, de visibilidade e de relação social, estão recobertos de símbolos, rituais e valores que estruturam e dão coesão às práticas e instituições sociais (Prado e Machado, 2008). A sexualidade, na lógica desclassificadora, foge da violência dicotômica dos sistemas de organização do conhecimento tradicionais e de suas aparentes liberdades de escolha.

Rich (1993) e Butler (2002) afirmam que a heteronormatividade é uma "ordem compulsória" que exige dos sujeitos uma coerência total entre um sexo, um gênero e uma conduta/desejo/afeto, que são obrigatoriamente heterossexuais (aspecto que se reflete homogeneizadamente nas assunções e categorias dos sistemas de organização do conhecimento). Percebe-se, assim, que a coerência do gênero se realiza na criação da ilusão do que seria "natural" para o corpo sexuado e do que pareceria "natural" para aqueles que afirmam ter esse corpo por agirem assim. Tudo o que não é natural não é considerado normal pelos classificadores, sai fora da norma, do padrão, do foco do sistema de organização do conhecimento e é empurrado às margens (Olson, 1997; Cornell, 1992). Aqueles que não se adequam a essa ordem são alocados na zona de exclusão, tornando-se ininteligíveis como pessoa, porque a identidade só pode ser estabelecida dentro das "leis que buscam estabelecer as linhas causais ou expressivas de conexão entre sexo biológico, gêneros constituídos culturalmente e a 'expressão' ou 'efeito' de ambos nas manifestações do desejo sexual nas práticas sexuais” (Butler, 2007: 72).

Butler (2002) define tais sujeitos como corpos abjetos, aqueles cujas vidas são consideradas ilegítimas e, portanto, quase impossíveis de se materializar, destacando ainda que o corpo abjeto "não se restringe de modo algum a sexo e a heteronormatividade. Relaciona-se a todo tipo de corpos cujas vidas não são consideradas vidas" e "cuja materialidade é entendida como não 
importante" (Prins e Meijer, 2002: 161). Assim, compreende-se que toda política identitária é "anti-diversitária", uma vez que a identidade não apenas não comporta, mas sim segrega toda e qualquer singularidade, "minoritiza" nos sistemas de classificação, em palavras de Campbell (2000). Logo, toda diferença é uma (des)identidade, uma vez que, ou o sujeito adota a moral da identidade ou a ética da diferença.

A esse respeito, convém lembrar que, conforme Medeiros (2008), os estudos iniciais sobre identidade abordavam justamente a crise enfrentada por grupos minoritários, tais como negros, judeus e minorias religiosas, até que foram generalizados para se pensar no conjunto da sociedade moderna. A identidade é pensada através de um vai-e-vem entre fundamentos psicosociológicos e culturais, buscando compreender “quem sou?", mas sempre tendo em vista que eu me constituo enquanto tal porque me relaciono socialmente, ou seja, o outro é fundamental na minha formação identitária.

Diante disso, este trabalho objetiva compreender as autonomeações praticadas em aplicativos de relacionamento de forma a esboçar uma primeira aproximação a uma classificação do domínio das homossexualidades masculinas, modalidades alternativas de sexualidade e de desejo no Brasil. Tal classificação é desenvolvida não por profissionais generalistas externos, mas sim considerando os próprios sujeitos pertencentes ao domínio (classificação natural) e as principais teorias e autores no domínio das homossexualidades, em uma abordagem de análise de domínio pragmatista que se opõe a puras induções empiristas ou sistemas universalistas. Esta primeira aproximação é um ato de autoempoderamento que influencia de forma direta as representações dos sujeitos, uma vez que, se o que fora construído sobre e em torno das homossexualidades alinha-se sobre a tríade pecado-crime-doença, tal prática configura-se como um rompimento com as linhas componentes dos dispositivos que punem os desvios da norma vigente, constituindo uma relação de saber/poder.

\section{Metodologia}

O presente estudo possui cunho documental, apoiado em pesquisa bibliográfica, sob a forma de cartografia. A mesma se constrói à medida que os afetos se manifestam, criando um território e, consequentemente, uma paisagem psicossocial cartografável (Rolnik, 1989; Guattari e Rolnik, 1996). Compreende-se que os objetos de análise carregam em si sua própria teoria. Se teoria é cartografia, tentou-se compreender as estratégias de manifestação do desejo no campo social. 
O corpus da pesquisa fora cartografado utilizando-se o Scruff (aplicativo mobile de interação social utilizado por homens que buscam relacionar-se afetivo-sexualmente com outros homens), recorrendo-se à técnica de Mineração de Textos por meio dos softwares Voyant Tools (https://voyant-tools. org/) e Wordcounter (https://wordcounter.net/), permitindo a visualização de correlações, coocorrências, fluxos e dispersão de temáticas textuais. A ferramenta utilizada para este estudo foi a nuvem de tags, compreendendo o corpus de 1.732 palavras extraídas de 1.005 títulos de perfis de usuários. $\mathrm{O}$ uso destes softwares se considera aceitável para esta primeira aproximação e se justifica por serem softwares livres e amplamente disponíveis no Brasil para registrar frequência de termos e gerar nuvens de palavras. No entanto, pode considerar-se limitados face a outros programas, como o software privado WordStat ou o software desenvolvido na UNAM, TermExt (http://www. corpus.unam.mx/termext/), que trabalham com algoritmos linguísticos e estatísticos ao nível de termo.

Utilizou-se da técnica de análise de conteúdo (Bardin, 2011) para identificação dos principais assuntos contemplados no corpus, alocando as categorias identificadas (Figura 1). A classificação da Figura 3 foi construída com base no conhecimento de especialistas no domínio, seguindo a abordagem de Hjørland e utilizando como garantia (Barité, 2018) a garantia epistemológica da comunidade LGBTQIA+ (Budd e Martínez-Ávila, 2016; Martínez-Ávila e Budd, 2017), justificando o salto do nível terminológico a uma classificação conceitual, de forma que a violência da hierarquia seja minimizada (Tennis, 2012). Ressalta-se que as heterossexualidades foram incorporadas ao estudo, em função da própria construção social. Compreende-se que a diferença não atua isolada da norma, mas estabelece uma relação simbiótica onde uma não pode existir sem a outra, pois a posição de uma é certificada pela outra.

\section{AnÁlises E RESUltados}

A análise dos termos coletados permite inferir que a pseudoliberdade, que sedimenta a sociedade administrada, intenta por uma identificação do indivíduo ao imediatamente dado, ao status quo, por meio de incentivo à fabricação e consumo de supérfluos, criando uma sucessão de falsas necessidades.

2 O Scruff é um aplicativo mobile direcionado a homossexuais masculinos que buscam interação afetivo sexual. Lançado em 2010 nos Estados Unidos, pode ser acessado tanto em $i O S$, Android e Apple Watch. Em 2017, o aplicativo alcançou a marca de 12 milhões de membros em todo o mundo, sendo no Brasil um dos três aplicativos mais populares entre o extrato social analisado. 
Este caráter repressivo está associado ao progresso da razão, que se caracteriza pela insuficiência do seu aspecto crítico, que foi suplantado pela formalidade técnica (uma tese que está alinhada ao pensamento de Max Horkheimer e Theodor Adorno acerca da instrumentalidade da razão), cujo impacto pode ser observado na reprodução dos meios de vida imposta pelo sistema ao exaurir. Nisto, os sujeitos que aceitam as condições determinadas objetivamente não veem possibilidades de protesto, e se adequam à mecanização da vida como essa se apresenta e não como poderia vir a ser.

$\mathrm{Na}$ sociedade unidimensional, para invalidar os conflitos dos sujeitos, ou qualquer forma de pensamento que contenha elementos transcendentes, a medicina, principalmente a psiquiatria, por meio da medicalização, "cura" os Édipos, Hamlets, Don Juans, Romeus, isto é, personagens arquetípicos de conflitos, solidão e ansiedade, para que se tornem dirigentes competentes, alinhados à produção e reprodução social. Se há algum drama nesse cenário, este só pode ser aceito dentro dos limites da publicidade.

No mundo virtual, cria-se um espectro, uma performance que se ancora no desejo. Tal compreensão engloba o entendimento de si, onde tal compreensão é certificada ao vislumbrar-se a representação dos termos que compõe a amostra (Figura 1).

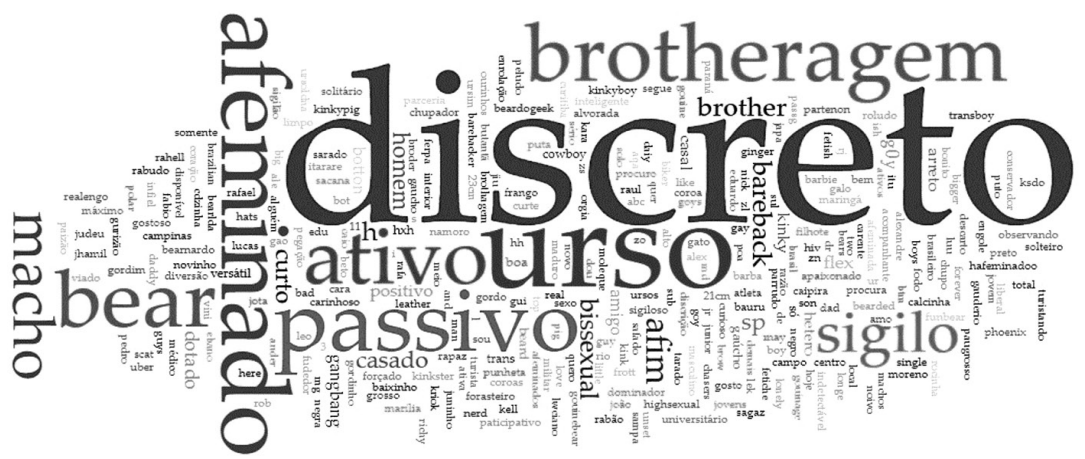

Figura 1. Nuvem de tags composta pelos termos adotados pelos usuários que servem como Identificação Fonte: elaborado pelos autores a partir do uso do software Voyant Tools, 2019

A nuvem de tags da Figura 1 demonstra como os usuários se compreendem em sua individualidade alinhando-se à reprodução social que ocorre na rede social analisada, sendo eles reduzidos aos termos desse universo.

Esse entendimento descortina-se por meio dos termos adotados pelos sujeitos para se autoidentificar no aplicativo (Quadro 1), onde a maneira de rotular do classificacionista que desenvolve o sistema indexador/classificador que o aplica é vivificado, refletindo estruturas de valores impostos pela nor- 
ma. O uso de termos "desviantes" por parte dos sujeitos que se autonomeiam no aplicativo objetiva uma aceitação social, em um processo no qual a identidade individual molda-se para ser assimilada pela identidade coletiva.

Cada termo utilizado pelos sujeitos revela mais do que apenas uma descrição de seu físico ou de seus desejos, pois é a forma como eles se compreendem e é a fonte do sentimento que constitui sua identidade individual. Essa compreensão pode ser verificada no Quadro 1.

\begin{tabular}{|c|c|c|c|c|c|}
\hline \multicolumn{2}{|c|}{$\begin{array}{c}\text { Densidade dos Títulos } \\
\text { compostos por uma palavra }\end{array}$} & \multicolumn{2}{c|}{$\begin{array}{c}\text { Densidade dos Títulos } \\
\text { compostos por duas palavras }\end{array}$} & \multicolumn{2}{c|}{$\begin{array}{c}\text { Densidade dos Títulos } \\
\text { compostos por três palavras }\end{array}$} \\
\hline discreto & $402(25 \%)$ & $\begin{array}{c}\text { passivo } \\
\text { discreto }\end{array}$ & $19(4 \%)$ & não curto afeminado & $8(4 \%)$ \\
\hline urso & $139(9 \%)$ & $\begin{array}{c}\text { macho } \\
\text { discreto }\end{array}$ & $18(4 \%)$ & passivo não-afeminado & $4(2 \%)$ \\
\hline afeminado & $71(4 \%)$ & discreto afim & $14(3 \%)$ & discreto de boa & $3(2 \%)$ \\
\hline brotheragem & $68(4 \%)$ & não curto & $10(2 \%)$ & ativo discreto dotado & $2(1 \%)$ \\
\hline bear & $66(4 \%)$ & não afeminado & $9(2 \%)$ & atv namoro discreto & $2(1 \%)$ \\
\hline sigilo & $43(3 \%)$ & ativo discreto & $9(2 \%)$ & casal de ursos & $2(1 \%)$ \\
\hline passivo & $43(3 \%)$ & atv discreto & $9(2 \%)$ & homem psv discreto & $2(1 \%)$ \\
\hline macho & $38(2 \%)$ & de boa & $8(2 \%)$ & não curto afeminados & $2(1 \%)$ \\
\hline ativo & $32(2 \%)$ & discreto sigilo & $8(2 \%)$ & partenon não afeminado & $2(1 \%)$ \\
\hline atv & $31(2 \%)$ & $\begin{array}{c}\text { curto } \\
\text { afeminado }\end{array}$ & $8(2 \%)$ & passivo discreto com & $2(1 \%)$ \\
\hline
\end{tabular}

Quadro 1. Densidade dos termos segundo sua composição

Fonte: elaborado pelos autores a partir do uso do software Wordcounter, 2019

Os termos com maior densidade na amostra são "discreto", "passivo discreto" e "não curto afeminado", objetivando afastar o indivíduo da representação de um homossexual "afeminado", ou seja, assegurar-lhe uma aceitação social devido ao reforço da sua masculinidade, modelo melhor assimilado pela heteronormatividade.

Outro termo recorrente e utilizado com o mesmo propósito é "macho", através do qual o sujeito destaca que, embora deseje outros homens, isso não anula sua masculinidade. O termo "brotheragem”, adaptação da palavra brother, representa uma parceria, informando que não se busca uma relação amorosa, mas sim uma brotheragem, ou seja, uma parceria masculina para relações sexuais, sem comprometer sua masculinidade e heterossexualidade.

Novamente, percebe-se a construção da identidade de um gay que não é "gay", ou seja, um homem que deseja relacionar-se sexualmente com outros homens, mas mantendo sua essência enquanto "macho", na medida em que 
não é "afeminado", pois se trata apenas de um homem "discreto" que deseja divertir-se com outro homem. Essa é a forma encontrada por esses usuários para serem aceitos pelo grupo social, sem terem de abrir mão de praticar seus desejos. Verifica-se que os indivíduos constituem sua identidade também por meio de imposições feitas pelo meio social, sendo uma maneira de identificação forçada.

O sexo figura enquanto componente do trabalho e das relações públicas, isto é, a libido torna-se uma mercadoria tanto da indústria tecnológica quanto da política. Nesta lógica, incita-se o desejo, numa aparente liberdade que, ao mesmo tempo, gera uma submissão do sujeito às relações de exploração do capitalismo tardio (onde a ideologia e as contradições da realidade estão imbricadas), cujo resultado é a pulverização do protesto e a criação de linhas de fuga como forma de resistência. Frente a isso, essa adaptação identitária torna-se por vezes uma dissonância diante da consonância dos sujeitos produtores de sequências da linha de montagem do desejo, que são ressignificados através do uso de termos desviantes.

Verifica-se, então, que esses sujeitos que buscam relativizar suas práticas sexuais por meio de termos desviantes, balizam-se na construção social de uma coerência entre um sexo, um gênero e uma conduta/desejo/afeto que produz dobras e sobreposições que se alinham segundo a lógica do sujeito em negociação com a sociedade.

Para confirmar a interpretação dos dados analisados nesta pesquisa, pode-se vislumbrar a própria essência do lucro capitalista que não se reduz ao campo da mais-valia econômica, mas se estende à tomada de poder da subjetividade, onde o desejo e sua prática tornam-se produtos de uma cultura de massa que produz indivíduos normalizados, articulados uns aos outros segundo sistemas hierárquicos de valores dissimulados, conforme destacam Guattari e Rolnik (1996).

Além disso, a interpretação feita aos dados coletados nesta pesquisa encontra respaldo na classificação do Domínio das Homosexualidades e Masculinas e Modalidades Alterativas de Sexualidade, Mazzei (1979) esboçou uma classificação bem-humorada estabelecendo os sete arquétipos de animais gays que se tornariam a base do atual "reino animal gay", aproximando os sujeitos de animais a partir de características físicas e comportamentais (Figura 2). 


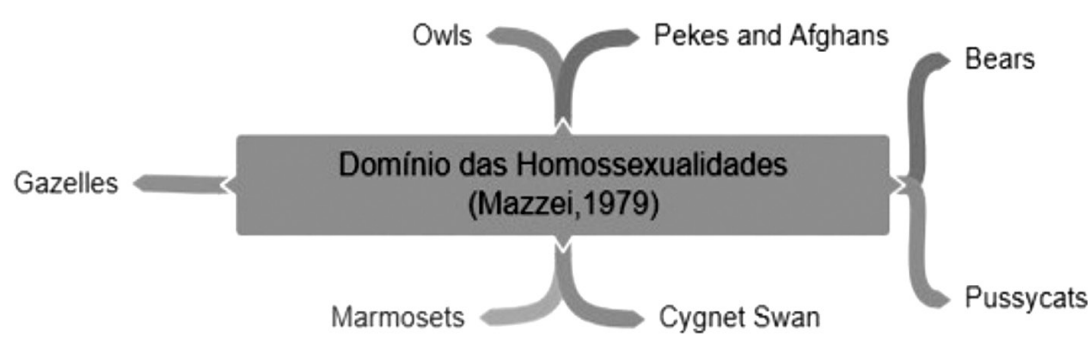

Figura 2. Classificação do Domínio das Homossexualidades (Mazzei, 1979)

Fonte: elaborado pelos autores, 2019

O que insurge no dominio das Homossexualidades Masculinas de forma bem-humorada em tempos hodiernos apresenta-se de forma complexa e multifacetada, como se pode observar na representação da classificação elaborada a partir do corpus deste estudo (Figura 3), onde determinados grupos se consolidaram enquanto subdomínio. Um exemplo é o grupo dos Ursos (Bears), ${ }^{3}$ que aufere largo espaço, consolidando-se enquanto subdomínio mais antigo e de maior abrangência. Seu subdomínio é subdividido em 18 (dezoito) subdivisões que agrupam características peculiares dentro de um mesmo subdomínio que agrega ainda duas subdivisões que se alicerçam nas relações afetivo-sexuais estabelecidas com os sujeitos que habitam o domínio ursófilo.

Ressalta-se que, nesse subdomínio, além das características físicas, a classificação foi refinada fazendo em tempos hodiernos uso dos marcadores sociais de diferença, ligados à compleição física, à idade e à raça, o que não acontece em nenhum outro grupo ou subgrupo no domínio das Homossexualidades Masculinas e Modalidades Alternativas de Sexualidade, principalmente no tocante à construção de níveis de alteridade e hierarquias entre os sujeitos.

Assim, ao visualizar-se a representação da Classificação das Homossexualidades Masculinas e Modalidades Alternativas de Sexualidade (Figura 3), observa-se uma segmentação de determinados grupos. Tal fenômeno refina o alcance das classificações de modo a alcançar sujeitos que não se enquadram a princípio nos grupos e subgrupos preestabelecidos e que apresentam uma forte identificação com eles.

3 O termo êmico urso é utilizado entre os homossexuais para designar, de forma geral, homens grandes (gordos ou musculosos), com abundância de pelos corporais e faciais e que se relacionam afetiva ou sexualmente com outros homens (Diniz, 2017). 


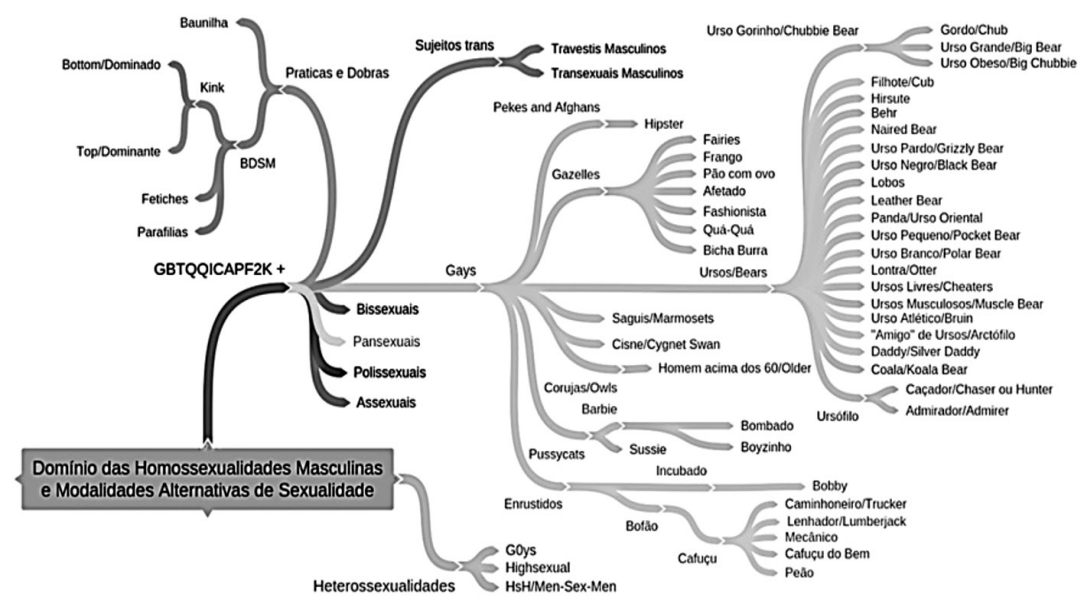

Figura 3. Classificação das Homossexualidades Masculinas e Modalidades Alternativas de Sexualidade Fonte: elaborado pelos autores, 2019

É fundamental perceber que, mesmo alocados em um mesmo domínio (homossexualidades masculinas e modalidades alternativas de sexualidade), existem grupos distintos que atuam em muitos casos como resistência aos padrões estabelecidos, inclusive por aqueles que foram lançados à margem em função de sua orientação do desejo, identidade de gênero ou mesmo sua prática sexual.

Logo, ao imergir no domínio das sexualidades humanas norteando-se por meio do viés da Organização da Informação e do Conhecimento, ancorando-se e dando origem a classificações além das linguagens documentárias, o contingente informacional que adentra a academia, sendo representado por intermédio de tesauros, taxonomias, vocabulários controlados e outras linguagens documentárias, comumente não foi criado a partir de autonomeações e autoclassificações exercitadas pelos praticantes de modalidades alternativas de sexualidade, mas sim tiveram sua origem no discurso médico, cientifico e religioso, orientadas por discursos hegemônicos que constituem a tríade Pecado-Crime-Doença, limitando o acesso, a representação e consequentemente a recuperação da informação. Por se tratar de construir e representar uma categoria social dominada, o cenário não apresenta a verossimilhança como aspecto central, fazendo com que a identificação, a representação e consequentemente a recuperação da informação acerca dos sujeitos se torne aquém do que é praticado na sociedade. 


\section{Considerações Finais}

A linguagem é um fenômeno sociocultural de expressão, tornando-se êmica de um indivíduo, grupo, classe, um organismo vivo que se transforma com o uso, visando intencionalidades, vontades e desejos. Como identificou-se neste estudo, seja por medo, vergonha ou preconceito, um homem que deseja sexualmente outro homem nem sempre se identifica com o termo "gay", uma vez que essa classificação lhe renderia estigmas sociais que ele pode não estar preparado para enfrentar. Assim, em sua autoclassificação, alguns sujeitos utilizam termos que provocam deslizamentos de sentido, afastando-os da identidade homossexual e reforçando sua masculinidade, baseando-se em estereótipos e preconceitos.

Para além de dominar os sistemas de classificação documentária, os estudos terminológicos contemporâneos têm como desafio compreender seu papel na reflexão acerca das interações sociais que resultam em hierarquias, estereótipos e estigmas que se manifestam através da linguagem. Em outras palavras, por trás de cada termo empregado por um grupo social, há uma vontade - ou mesmo uma vontade reprimida. Cada termo é cuidadosamente escolhido para provocar um determinado sentido, especialmente quando os sujeitos utilizam esse termo para representar a si mesmos. Um termo nunca está sozinho, ele revela aspectos sobre quem o produziu e está repleto de elementos identitários.

O presente estudo corresponde a uma primeira aproximação ao desenvolvimento de uma classificação sobre homossexualidades masculinas, seguindo uma abordagem pragmatista ou de análise de domínio, informada pelo conhecimento teórico de especialistas e pela participação dos indivíduos do domínio. Esta classificação poderá ser aplicada em um posterior momento no desenvolvimento de sistemas de organização do conhecimento, como taxonomias, tesauros, glossários e dicionários, que possam ser utilizados em unidades de informação específicas, fortalecendo de forma intrínseca e extrínseca o domínio e os objetivos e interesses dos indivíduos que o conformam.

\section{REFERÊNCIAS}

Badinter, Elisabeth. 1993. XY: sobre a identidade masculina. Rio de Janeiro: Ed. Nova Fronteira.

Bardin, Laurence. 2011. Análise de Conteúdo. Lisboa: Edições70.

Barité, Mario. 2018. "Literary warrant”. Knowledge Organization 45 (6): 517-536. Bourdieu, Pierre. 2002. A Dominação Masculina. Rio de Janeiro: Bertrand Brasil. 
Budd, John M. e Daniel Martínez-Ávila. 2016. "Epistemic warrant for Categorizational Activities in Knowledge Organization”, en Knowledge Organization for a Sustainable World: Challenges and Perspectives for Cultural, Scientific, and Technological Sharing in a Connected Society, Proceedings of the Fourteenth International ISKO Conference 27-29 September 2016 Rio de Janeiro, Brazil, editado por José Augusto Chaves Guimarães, Suellen Oliveira Milani y Vera Dodebei, 142-145. Würzburg: Ergon.

Butler, Judith P. 2002. Cuerpos que importam: sobre os limites materiais e discursivos do sexo. Buenos Aires: Paidós.

Butler, Judith P. 2007. El género en disputa. El feminismo y la subversión de la identidad. Barcelona: Paidós.

Campbell, D. Grant. 2000. "Queer theory and the creation of contextual subject access tools for gay and lesbian communities”. Knowledge organization 27 (3): 122-131.

https://doi.org/10.5771/0943-7444-2000-3-122

Campbell, D. Grant, Jose Augusto Chaves Guimarães, Fabio Assis Pinho, Daniel Martínez-Ávila e Francisco Arrais Nascimento. 2017. “The Terminological Polyhedron in LGBTQ Terminology: Self-Naming as a Power to Empower in Knowledge Organization". Knowledge Organization 44 (8): 586-591. https://doi.org/10.5771/0943-7444-2017-8

Cornell, Drucilla. 1992. The philosophy of the limit. New York: Routledge.

Deleuze, Gilles. 1996. "O que é dispositivo?" en O mistério de Ariana, editado por G. Deleuze, 83-96. Lisboa: Passagens.

Diniz, Antony Henrique Tomaz. 2017. "Os corpos dos ursos: uma etnografia do meio ursino paulistano”. Dissertação de mestrado, Universidade Estadual de Campinas, Campinas, SP, Brasil.

Foucault, Michel. 1988. História da sexualidade I: a vontade de saber. Rio de Janeiro: Edições Graal.

Foucault, Michel. 2000. Sobre a história da sexualidade. Rio de Janeiro: Graal.

Foucault, Michel. 2013. Vigiar e punir: história da violência nas prisões. 41. ed. Petrópolis: Vozes.

García Gutiérrez, Antonio. 2009. La identidad excesiva. Madrid: Biblioteca Nueva.

Guattari, Félix e Suely Rolnik. 1996. Micropolítica: Cartografias do Desejo. 4. ed. Rio de Janeiro: Vozes.

Hjørland, Birger. 2002. "Principia Informatica. Foundational Theory of Information and Principles of Information Services", en Emerging Frameworks and Methods. Proceedings of the Fourth International Conference on Conceptions of Library and Information Science (CoLIS4) editado por Harry Bruce, Raya Fidel, Peter Ingwersen y Pertti Vakkari, 109-121.Greenwood Village, Colorado, USA: Libraries Unlimited.

Hjørland, Birger. 2009. "Concept theory". Journal of the American Society for Information Science and Technology 60 (8): 1519-1536.

Hjørland, Birger. 2013. "Theories of Knowledge Organization-Theories of Knowledge”. Knowledge Organization 40 (3): 169-181.

Hjørland, Birger. 2016. "Knowledge organization”. Knowledge Organization 43 (6): 475-484.

Hjørland, Birger. 2017. “Domain Analysis”. Knowledge Organization 44 (6): 436-464. 
Keilty, Patrick e Richard P. Smiraglia. 2016. “Gay Male Nomenclature”, en Knowledge Organization for a Sustainable World: Challenges and Perspectives for Cultural, Scientific, and Technological Sharing in a Connected Society: Proceedings of the Fourteenth International ISKO Conference 27-29 September 2016 Rio de Janeiro, Brazil, editado por José Augusto Chaves Guimarães, Suellen Oliveira Milani y Vera Dodebei, 579-586. Würzburg: Ergon.

Louro, Guacira Lopes. 2010. Gênero, sexualidade e educação: uma perspectiva pós estruturalista. 11. ed. Petrópolis: Vozes.

Machado, Luís Miguel Oliveira, Daniel Martínez-Ávila e Maria da Graça Melo Simões. 2019 "Concept theory in Library and Information Science: an epistemological analysis of the literature". Journal of Documentation 75 (4): 876-891.

Mai, Jens-Erik. 2011. "The modernity of classification”. Journal of Documentation 67 (4): $710-730$.

Martínez-Ávila, Daniel e John M. Budd. 2017. "Epistemic warrant for categorizational activities and the development of controlled vocabularies". Journal of Documentation 73 (4): 700-715.

Martínez Ávila, Daniel e José Augusto Chaves Guimarães. 2013. "Library classifications criticisms: universality, poststructuralism and ethics". Scire 19 (2): 21-26.

Martínez-Ávila, Daniel, Marcio Ferreira e José L. Magro. 2015. "Aplicación de la Teoría Crítica de Raza en la organización y representación del conocimiento”. Scire 21 (2): 27-33.

Martínez-Ávila, Daniel, Rafael Semidão e Marcio Ferreira. 2016. "Methodological Aspects of Critical Theories in Knowledge Organization”. Knowledge Organization 43 (2): 118-125.

https://doi.org/10.5771/0943-7444-2016-2

Mazzei, George. 1979. “Who's Who in the Zoo?” The Advocate: 42-43.

Mazzocchi, Fulvio. 2018. "Knowledge organization system (KOS)". Knowledge Organization 45 (1): 54-78.

Medeiros, Joao Luiz. 2008. Identidades em movimento: nação, cyberespaço, ambientalismo e religião no Brasil contemporâneo. Porto Alegre: Sulina.

Miskolci, Richard. 2009. "O armário ampliado: notas sobre sociabilidade homoerótica na era da internet”. Revista Gênero 9 (2): 171-190. https://doi.org/10.22409/rg.v9i2.88

Moreira, Thami Amarílis Straiotto. 2011. "O ato de nomear- da construção de categorias de gênero até a abjeção”. Trabalho apresentado no XIV Congresso Nacional de Linguística e Filologia, Rio de Janeiro, 23-27 agosto.

Olson, Hope A. 1997. "The Feminist and the Emperor's New Clothes: Feminist Deconstruction as a Critical Methodology for Library and Information Studies”. Library E Information Science Research 19 (2): 181-198. https://doi.org/10.1016/S0740-8188(97)90042-6

Olson, Hope A. 2002. The power to name: locating the limits or subject representation in libraries. Dordrecht: Kluwer Academic Publisher.

Prado, Marco Aurélio Máximo e Frederico Viana Machado. 2008. Preconceito contra homossexualidades: a hierarquia da invisibilidade. São Paulo: Cortez Editora. 
Prins, Baukje e Irene Costera Meijer. 2002. "Como os corpos se tornam matéria: entrevista com Judith Butler”. Revista Estudos Feministas 10 (1): 155-167. https://doi.org/10.1590/S0104-026X2002000100009

Rich, Adrienne. 1993. "Compulsory heterosexuality and lesbian existence", en Adrienne Rich's Poetry and Prose, editado por Barbara Charlesworth Gelpi y Albert Gelpi, 203-224. New York/London: W.W. Norton \& Company.

Rolnik, Suely. 1989. Cartografia Sentimental: Transformações contemporâneas do desejo. São Paulo: Editora Estação Liberdade.

Souza, Renato Rocha, Douglas Tudhope e Mauricio B. Almeida. 2012. "Towards a Taxonomy of KOS: Dimensions for Classifying Knowledge Organization Systems". Knowledge Organization 39 (3): 179-192.

Tennis, Joseph T. 2012. "A Convenient Verisimilitude or Oppressive Internalization?: Characterizing the Ethical Augments Surrounding Hierarchical Structures in Knowledge Organization Systems". Knowledge Organization 39 (5): 394 397.

Vergueiro, Waldomiro. 1994. "Ética profissional versus ética social: uma abordagem sobre os mitos da biblioteconomia". Palavra-chave 8: 8-12.

Para citar este texto:

Nascimento, Francisco Arrais, Luis Fernando Herbert Massoni, Rafael da Silva Shirakava, Fabio Assis Pinho e Daniel Martínez-Ávila. 2020. "Autonomeação e autoclassificação das homossexualidades masculinas e sexualidades alternativas no Brasil”. Investigación Bibliotecológica: archivonomía, bibliotecología e información 34 (84): 151-168. http://dx.doi.org/10.22201/iibi.24488321xe.2020.84.58209 